an ad hoc CEC working group is being discussed with Brussels.

\section{ILL Agreement Signed}

The protocol to officially extend until 2003 the agreement between France, German and the UK covering the Institut Laue-Langevin, Grenoble, was signed in Paris on 25 March. This completes formal arrangements for operation, scheduled to start in mid-1994, of the ILL's High Flux Reactor after refurbishment.

\section{ESRF Users' Meeting}

The ESRF in Grenoble will hold a Users' Meeting on 24-25 September 1993 to give prospective users the information they require to make proposals for scientific experiments on eight of the first beamlines. For information, contact Mrs. R. Mason, ESRF, BP 220, F-38043 Grenoble [tel./fax: +33 () 76 882014 / 76882160 ; mason @ ill.fr].

Four beamlines are already operating, and the decision to instrument 11 more on the part of the experimental floor which has been treated for vibrations by injecting grout will be taken at the end of April. The ESRF Council has approved installations proposed by four Cooperating Research Groups and Y. Petroff, the new ESRF Director, who took over from R. Haensel when his term-of-office ended on 31 December, reports that applications for three more CRG's are expected shortly. The ESRF synchrotron is operating to specifications at $100 \mathrm{~mA}$ and $6 \mathrm{GeV}$ with a beam lifetime time of 10 hours. If the decision on the floor is favourable, regular user operation begins in autumn 1994 with the eight lines, implying that there is only a 3-4 months delay relative to the date at which it was originally planned to have this number of lines available.

\section{Physique en Herbe 93}

The 10th Physique en Herbe conference for young physicists takes place at the Institut National des Sciences et Techniques Nucléaires in Saclay near Paris on 28 June-2 July 1993. Contact: Oliver Beckers, PCM, Université de la Vallée de Marne, 2, allée Jean-Renoir, F-93160 Noisy-le-Grand (tel./fax: +33-1-49326092/442752 33).

\section{EPS-9}

GENERAL CONFERENCE

Florence 14-17 September 1993

Deadline for registration at reduced rates: 15 May 1993

Contact for registration: Cong. Secretariat

OIC, Via La Marmora, 24

1-50121 Florence

Tel./fax: +39 (55) $5000631 / 5001912$

\title{
Armenia and Bosnia
}

Armenian physicists are presently working under terrible conditions and help is urgently needed to maintain some semblance of professional life. Roger Balian, the Editor-in-Chief of Europhysics Letters, has launched an appeal that aims to collect funds to cover the trave expenses of Armenian physicists collaborating with physicists elsewhere in Europe. Help to pay the membership fees to EPS and to participate in EPS activities is also envisaged as the Armenian Physical Society was admitted as an EPS member by Council on 26 March.

Donations should be sent either as cheques made out in French francs to Professor $R$. Balian, 36, rue Ernest Renan, F-92190 Meudon, or as postal transfers to Post Office account number CCP 286-79 D Paris, giving as reference "Armenia Appeal".

The French Physical Society's Human Rights Commission has launched an "aide de première urgence" scheme for physicists from Bosnia. A foreign currency bank account has been opened in Zagreb and two members of the Society based there are distributing small grants directly to recipients. The scheme started with significant donation to the French Physical Society, to which others are now being added.

Further donations are most welcome. They can be sent either as cheques made out in French francs to Bosnia Appeal, c/o Human Rights Commission, Société Francaise de Physique, 33, rue Croulebarbe, F-75013 Paris, or as postal transfers to Post Office account number CCP 227-92 E 020 Paris, giving as reference "Bosnia Appeal".

Those interested in establishing similar schemes from other countries might wish to obtain information from F. Lalöe, Laboratoire de Spectroscopie Hertzienne de l'ENS, 24, rue Lhomond, F-75231 Paris Cédex 05. Tel.: +33 (1) 470754 13; fax: +33 (1) 453500 76; email: laloe @ physique.ens.fr

\section{Why MathSoft Overseas has a centre of excellence for Mathematica at CERN}

\section{Because Mathematica responds to CERN's needs for a comprehensively} supported mathematical software package for physics and engineering.

- Mathematica represents a genuine revolution in the art of computing.

Collects in a single package available on any computer:

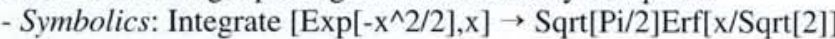

- Numerics: Erf[1.2] $\rightarrow 0.910314$

- Graphics: Plot[Erf[x],\{x,-4,4\}, AxesLabel $\rightarrow\{$ "x","y"\}]

- List processing: Erf[\{1.1,2.5,-3.4\}] $\rightarrow\{0.7747609,0.9991862,-0.9999965\}$

- Functional programming with pattern recognition:

Factorial function $\rightarrow$ fac[n_Integer/;n>0]: $=\mathrm{n}$ fac $[n-1] ;$ fac $[0]=1$

- The Descartes ${ }^{\mathrm{TM}}$ Library extends Mathematica

- Euclidian geometry: all Euclidian geometry on point, straight, circle, conics, lines, and polygons. Application to rigorous drawing, theorem testing, CAD, desktop publishing, and any graphics technique.

- Differential geometry of curves and surfaces.

- Visualization: pre-processing of objects to be visualized in the form of Cartesian surfaces, parametrric lines and surfaces, and geometric solids; data representation in needle tower or interpolating surfaces. Interface to AVS ${ }^{\mathrm{TM}}$.

- Integration of Mathematica by MathSoft Overseas in process control using UNIX

- Dedicated technical and commercial support

- Optimum pricing (volume discount, educational grants, site licensing, etc.).

- Three-day courses: Introduction to Mathematica, symbolic programming.

- Consulting on specific problems.

To become a centre of excellence in Mathematica, please contact:

MathSoft Overseas, CP 641, CH-1211 Geneva 3

Tel.: +41-22-346 52 60; Fax: +41-22-346 5939

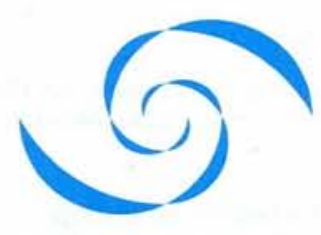

Visualization of a parametric surface

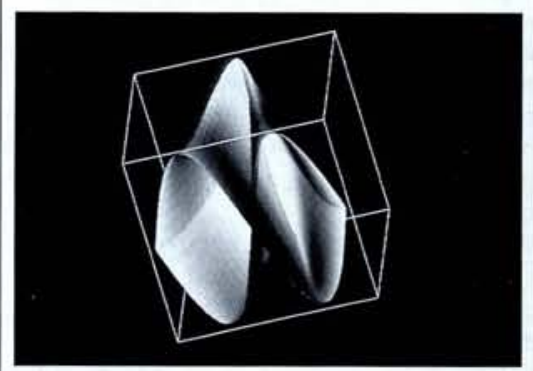

A figure produced with the statement: View[ $\left.\left[\operatorname{Cos}[\mathrm{u}], \operatorname{Sin}[\mathrm{v}], \mathrm{u}^{*} \mathrm{v} / 10\right\},\{\mathrm{u}, \mathrm{Pi}, \mathrm{Pi}\},\{\mathrm{v}, \mathrm{Pi}, \mathrm{Pi}\}\right]$ Descartes Visualization acts as the link between Mathematica and the AVS ${ }^{\mathrm{TM}}$ visualization program. The rigorously defined object could, for example, represent stream flow. 